\title{
ANALISIS KONFLIK TOKOH UTAMA DALAM NOVEL AIR MATA TUHAN KARYA AGUK IRAWAN M.N
}

\author{
Rini Agustina \\ IKIP PGRI Pontianak, brentex32@yahoo.co.id
}

\begin{abstract}
This study focuses on internal conflicts in the novel Air Mata Tuhan works Aguk Irawan M.N. The method in this article uses descriptive method and form of qualitative research. Psychology humanities is used as an approach in this article. Data collection technique used is the technique of documentary studies to reviewing creation humanities. Data collection tool used is the Human Instrument with the help of card data recorder. Technique authenticity of data used are, triangulation investigator, theory triangulation and inspection peers through discussion. The analysis technique used is the study of the contents. External conflict contained in the novel Tears God works Aguk Irawan M. N based on the analysis that researchers do, namely social conflict tangible problem accusation, strife, oppression, and opposition. Internal conflicts contained in the novel Tears God works Aguk Irawan M. N based on the analysis that researchers do that is the inner conflict in the form of expectations, and the conflicts between the two desires.
\end{abstract}

Key Words: literature, conflict, novel

\section{PENDAHULUAN}

Karya sastra merupakan sistem tanda yang mempunyai makna yang mempergunakan medium bahasa. Karya sastra mencerminkan masyarakat pada suatu zaman bisa juga dianggap sebagai dokumen social budaya, meskipun unsurunsur imajinasi tidak bisa dilpaskan begitu saja, sebab tidak mungkin seorang seorang pengarang dapat berimajinasi jika tidak ada kenyataan yang melandasinya. Mengkaji sastra adalah suatu hal yang menarik dan tidak pernah terhenti selagi karya sastra itu masih diciptakan. Hal ini disebabkan sastra memiliki hubungan yang cukup erat dengan kehidupan khususnya pengarang dan pembacanya. Sastra adalah suatu bentuk kehidupan dan kekayaan yang tidak ternilai harganya. 
Sebagai karya yang bersifat imajinatif, karya sastra terbagi ke dalam tiga jenis genre sastra, yaitu prosa, puisi, dan drama. Prosa dalam pengertian kesusastraan juga disebut fiksi dan teks naratif. Dalam hal ini fiksi menawarkan berbagai permasalahan manusia dan kehidupan. Namun, karena fiksi merupakan cerita rekaan atau khayalan saja, maka dari itu berbagai masalah kehidupan tersebut di olah dengan sungguh-sungguh sedemikian rupa oleh pengarang sesuai dengan persepsinya untuk dituangkan ke dalam karya sastra.

Karya sastra merupakan satu diantara hasil seni dan ada yang menyebut sebagai suatu karya fiksi. Cerita rekaan adalah hasil olahan sastrawan berdasarkan pandangan dan tataran pengolahan tentang p eristiwa-peristiwa yang berlangsung dalam khayalan saja. Dengan demikian, karya fiksi merupakan suatu karya naratif yang isinya tidak menyaran pada kebenaran sejarah (Nurgiyantoro, 2010:2).

Satu diantara karya sastra yang merupakan gambaran kehidupan manusia yang dituangkan dalam bentuk tulisan oleh penulis dengan imajinasinya yaitu novel. Novel merupakan bentuk karya sastra yang dapat dengan bebas berbicara tentang kehidupan yang dialami oleh manusia dengan berbagai peraturan dan norma-norma dalam interaksinya dengan lingkungan sehingga dalam karya sastra seperti novel terdapat makna tertentu tentang kehidupan.

Goldman (Faruk, 2012:90) mendefinisikan novel sebagai cerita tentang suatu pencarian yang terdegradasi akan nilai-nilai yang otentik yang dilakukan oleh seorang hero yang problematik dalam sebuah dunia yang juga terdegradasi. Novel adalah cerminan kehidupan sehingga isi dari novel tersebut juga terdapat konflik layaknya dalam kehidupan nyata.

Konflik dalam kehidupan sehari-hari merupakan peristiwa yang sangat tidak diinginkan kehadirannya untuk menimpa diri seseorang, sedangkan dalam sebuah karya sastra tidak demikian adanya. Konflik dalam novel merupakan bagian penting untuk membangun struktur alur. Konflik dalam sebuah karya sastra justru menjadi sesuatu yang dibutuhkan pembaca sebagai sebuah pengalaman hidupnya.

Konflik adalah sesuatu yang dramatik, mengacu pada pertarungan antara kekuatan yang seimbang dan menyiratkan adanya aksi dan aksi balasan, menurut 114 | E-ISSN: 2527-8754 http:// journal.unesa.ac.id/index.php/Paramasastra 
Wellek \& Werren (Nurgiyantoro, 2013:179). Konflik dibagi menjadi dua yaitu konflik internal dan konflik eksternal. Konflik internal adalah konflik yang terjadi dalam hati dan fikiran, dalam jiwa seorang tokoh (atau : tokoh-tokoh) cerita. Konflik ekternal adalah konflik yang terjadi antara seorang tokoh dengan suatu yang diluar dirinya, mungkin dengan lingkungan alam mungkin lingkungan manusia atau tokoh lain.

Penelitian ini dikhususkan pada konflik tokoh utama. Alasannya, antara konflik dan tokoh utama mempunyai hubungan yang erat dan bersifat timbal balik. Konflik hadir sebagai bayang-bayang perjalanan hidup tokoh. Semakin banyak liku itu disediakan pengarang, maka semakin panjang perjalanan hidup dan rentang waktu yang dibutuhkan tokoh untuk akhir cerita. Konflik dalam novel merupakan bagian penting untuk membangun struktur alur. Konflik dalam sebuah karya sastra justru menjadi sesuatu yang dibutuhkan pembaca sebagai sebuah pengalaman hidupnya.

Alasan peneliti memilih novel Air Mata Tuhun adalah sebagai berikut, yang pertama adalah novel ini terinspirasi dari kehidupan nyata dan kisah yang sangat inspiratif. Kedua, berdasarkan hasil prariset yang dilakukan penulis, dalam novel Air Mata Tuhan banyak mengandung konflik tokoh utama, satu diantaranya yaitu ketika Fisha mengetahui bahwa suaminya hendak menikah lagi. Ketiga, novel Air Mata Tuhan belum ada yang menjadikan novel ini sebagai bahan penelitian. Keempat, pengarang novel Air Mata Tuhan yaitu Aguk Irawan M. N merupakan penulis novel best seller yang sudah terkenal dengan karya-karyanya yang inspiratif. Fokus masalah dalam artikel ini adalah bagaimanakah konflik internal dalam novel Air Mata Tuhan karya Aguk Irawan M.N.

Metode yang digunakan dalam artikel ini adalah metode deskriptif kualitatif. Pendekatan yang digunakan adalah pendekatan psikologis sastra. Data dalam penelitian ini berupa kutipan novel yang mengandung konflik batin. Sumber data dalam penelitian ini adalah novel Air Mata Tuhan karya Aguk Irawan M.N. Teknik pengumpulan data menggunakan analisis dokumen dengan alat pengumpulan data adalah peneliti sendiri sebagai instrumen kunci. Validitas 
data dalam penelitian ini adalah triangulasi teori, ketekunan pengamatan dan pemeriksaan teman sejawat. Teknik analisis data yang digunakan dalam penelitian ini adalah analisis isi (content analysis).

\section{PEMBAHASAN}

\section{Konflik Eksternal dalam Novel Air Mata Tuhan Karya Aguk Irawan M.N}

Konflik eksternal adalah konflik yang terjadi antara seorang tokoh dengan sesuatu yang di luarnya, mungkin dengan lingkungan alam, mungkin lingkungan manusia atau tokoh lain.

Berdasarkan analisis yang dilakukan oleh peneliti, di dalam novel Air Mata Tuhan karya Aguk Irawan M.N, terdapat banyak kutipan yang menggambarkan konflik sosial tokoh utama. Adapun Konflik sosial tokoh utama dalam novel Air Mata Tuhan dalam karya Aguk Irawan M.N adalah konflik yang disebabkan kontak sosial antarmanusia. Ia antara lain berwujud masalah penuduhan, penindasan, percekcokan, pertentangan, atau kasus-kasus hubungan sosial lainnya. Hal ini berkaitan langsung dengan karakter tokoh utama dalam menjalani kehidupan.

\section{Penuduhan}

"Ayah, apakah ini akan segera berakhir? Ayah kemana saja? Mengapa Ayah berubah? Aku kangen sama Ayah? Aku kangen belaian kasih sayang ayah? Aku kangen dengan manjanya Ayah? Aku kesepian Ayah? Dan satu hal lagi yang harus Ayah tau, bahwa aku tidak pernak berzinah?”. (Irawan, 2014:3)

Kutipan tersebut menggambarkan konflik yang dialami oleh Fisha kepada suaminya. Fisha merasa kehangatan suaminya telah hilang kepadanya. Konflik di rumahnya mulai terasa setelah Fisha melihat perubahan suaminya terhadapnya. Terlebih lagi suaminya menuduh dia telah berzina dengan Hamzah. Fisha selalu menanyakan didalam hatinya kemana suaminya yang dulu. Kemana Fikri yang dulu dan kemana kehangatan yang selalu Fikri tunjukan terhadapnya. Konflik sosial dalam kutipan tersebut ditujukkan dari perubahan sikap suami Fisha. 
Penuduhan Fikri terhadap Fisha yang menimbulkan penuduhan yang tiada henti terhadap Fisha. Kutipan lain yang menunjukkan penuduhan terdapat pada.

"Aku minta maaf, Ayah, telah membuat mu susah. Maafkan atas segala kesalahan ku. Di dunia ini, hanya satu laki-laki yang benar-benar ku cintai dan kusayangi. Adalah kau. Bukan yang lain. Maafkan hatiku bila-bila aku pernah melukai hati mu, Ayah...”. (Irawan, 2014:3)

Kutipan tersebut merupakan Penuduhan yang dilakukan Fikri terhadap Fisha. Apa yang dituduh oleh suaminya itu tidak benar dan ketidakpercayaan yang dirasakan oleh Fikri telah Fisha jelaskan berulang-ulang kali, dan Fisha juga menggatakan maaf karna telah melukai perasaan suaminya. Kutipan lain yang menunjukkan penuduhan berikut ini.

"Jika aku hanya mengejar hartamu, aku tak mungkin setiap hari menangis karena menderita mencintaimu". (Irawan, 2014:10)

Kutipan tersebut menunjukan bahwa Fikri menuduh Fisha mencintainya hanya karena harta semata. Penuduhan tersebut termasuk dalam konflik sosial yang merupakan penuduhan. Fikri mengira Fisha hanya mengiginkan hartanya saja, oleh karena itu, sifat Fikri berubah. Dan Fisha menjelaskan kalau dia hanya mencintai harta suaminya kenapa dia memilih Fikri sedangkan pada waktu itu banyak laki-laki yang menyukainya. Akibat yang ditimbulkan dalam konflik tersebut Fisha hanya bisa menangis dan tidak sanggup harus menjelaskan terhadap suaminya. Kutipan lain yang menunjukan penuduhan berikut ini.

"Demi Allah, aku tidak seperti yang kau kira, Hamzah. Dia mencintaiku karena Allah, dan aku tak pernah mendengar kau ungkapkan hal yang sama kepada ku selama ini”.(Irawan, 2014:175)

Kutipan tersebut mengambarkan Fisha lebih memilih Fikri dibandingkan dengan Hamzah. Karena, Fikri mencintai dirinya karena Allah semata. Sedangkan, Hamzah tidak ungkapkan hal yang sama kepadanya selama ini. 
Hamzah menuduh Fisha memberi harapan yang tidak jelas terhadap dirinyanya. Oleh karena itu, Hamzah marah kepada Fisha. Kutipan tersebut termasuk dalam konflik sosial yang berupa penuduhan Hamzah terhadap Fisha. Kutipan lain yang menunjukkan penuduhan berikut ini.

"Lihat saja kalau ibu tak percaya. Perempuan itu minta macam-macam. Baju, tas. Oh abang bisa miskin, bu. Ibu ingat, dia sudah menggerogoti harta abang. Kalung, gelang, cincin... dan hari ini baju-baju. Itu puluhan juta, bu. apa ibu terus membiarkan perempuan miskin dan rendah itu seperti itu?", (Irawan, 2014:242)

Dian dan Ibunya merencanakan sesuatu untuk menghasut Fikri. Dian masih saja mengadu yang tidak-tidak kepada ibunya bahwa Fisha benar-benar akan menghabiskan harta Fikri. Walau pun Fisha tidak pernah meminta apa-apa kepada Fikri.

Penuduhan yang dilakukan Dian dan Ibu Fikri terhadap Fisha termasuk dalam konflik sosial yang berupa penuduhan. Yang akan memudarka kepercayaan Fikri terhadap Fisha dan membuat Fikri menjadi semakin hati-hati terhadap Fisha. Karena Fikri tidak mau menjadi anak yang durhaka. Oleh sebab itu, Fikri lebih percaya pada ibunya dari pada Fisha meski pun sebenarnya Fikri tahu bahwa Fisha adalah istri yang baik bagi dirinya. Kutipan lain yang menunjukkan penuduhan berikut ini.

"Astagfirullah, ayah ternyata tidak mempercayaiku. Demi Allah, ayah, antara aku dan dia tidak ada apa-apa".(Irawan, 2014:252)

Kutipan tersebut mengambarkan bahwa Fikri masih tidak mempercayai Fisha dan Fikri masih saja menuduh Fisha berzina sama Hamzah pedalah Fisha udah menjelaskannya berulang-ulang kali. Penuduhan tersebut masuk dalam konflik sosial yang berupa penuduhan. Kutipan lain yang menunjukkan penuduhan berikut ini.

"Kau menyakiti perasaan ku ayah. Demi Allah aku tak seperti apa yang ada didalam bayanganmu itu. Aku bisa menjaga diriku. Tak ada satu pun laki-laki yang menyentuhku. Kenapa ayah tak mempercayaiku. Demi Allah, aku cinta kau, ayah. Aku sayang kau. Sejak kau ucapkan perkataan 
itu, sejak itu aku yakin bahwa engkaulah yang aku pilih. Haruskah aku bercerita bagaimana kata-kata telah mendebarkan jantungku, ayah, takkala kau bawa asma Allah dalam cintamu kepadaku, tatkala itu pula aku bertasbih memuji Allah karena rasa bahagiaku dicintai engkau?’.(Irawan, 2014:254)

Kutipan tersebut menunjukan bahwa Fikri menuduh Fisha berzina. Penuduhan tersebut termasuk dalam konflik sosial yang berupa penuduhan. Yang mengakibatkan perasaan Fisha hancur dan kecewa terhadap suaminya yang selalu dan selalu mempermasalahkan masa lalunya dengan Hamzah tersebut. Fisha sudah menjelaskan berkali-kali tetap saja Fikri masih tidak percaya. Kutipan lainyang menunjukkan penuduhan terdapat pada.

“Kau berzina dengannya!” vonis Fikri”. (Irawan, 2014:324)

Fikri menuduh Fisha telah berzina di belakangnya. Penuduhan Fikri terhadap Fisha termasuk dalam konflik sosial yang berupa penuduhan. Yang menbuat Fikri semakin marah dan memvonis Fisha telah berzina dengan Hamzah. Adapun kutipan yang menunjukkan penuduhan berikut ini.

"Tapi, apa yang telah kau lakukan sebelum ku nikahi kamu, heh? Kau pernah melakukan 'sesuatu' apa dengannya?'.(Irawan, 2014:324)

Fikri masih saja menunduh dan membentak Fisha. Fikri sama sekali tidak mempercayai Fisha dan mendengar ucapan Fisha. Masih saja Fikri mengira bahwa Fisha pernah melakukan sesuatu dengan Hamzah sebelum Fikri menikahi Fisha. Kutipan tersebut menunjukan penuduhan Fikri terhadap Fisha yang menimbulkan konflik yang begitu besar dalam rumah tangga Fikri dan Fisha.

\section{Percekcokan}

Kutipan yang menunjukkan percekcokan terdapat pada kutipan berikut.

"Fisha : Rumah ini adalah milik almarhum ayah, yang telah diwasiatkan almarhum ayah untuk diberikan kepada saya dari almarhum nenek saya. Dan sawah yang di sana itu telah diberikan pada adik saya. Seharusnya bapak bertanya dulu, menyelidik dulu, benar tidak ini milik pak Parwito". 
"Pak Hamdi : Dik, saya ini orang tua. Kalau adik memaksakan pendapat adik, saya pun bisa melakukannya. Adik bilang adik mahasiswa. Tentu adik tahu, urusan seorang penjual dan pembeli ada pada urusan jual-belinya, bukan usut-mengusut ini tanah dan rumah siapa. Perkara rumah ini telah diberikan kepada adik, itu bukan urusan saya. Saya telah membelinya dengan sah. Dan dengan sah pula, rumah ini menjadi milik saya".(Irawan, 2014:81)

Kutipan tersebut menunjukan percekcokan antara Pak Hamdi dan Fisha, karena Rumah dan Sawah yang telah diwasiatkan almarhum Ayahnya dari neneknya telah dijual oleh pamannya kepada pak Hamdi. Fisha marah karena, pak Hamdi membeli rumah almarhum ayahnya tanpa menyelidik terlebih dulu apakah rumah tersebut benar-benar punya pamannya atau tidak.

Percekcokan antara pak Hamdi dan Fisha mengakibatkan habisnya kesabaran Fisha tanpa berpikir bahwa yang dihadapinya itu adalah orang tua. Karena Fisha begitu kesal dan marah setelah tahu bahwa Rumah yang diwasiatkan almarhum Ayahnya telah dijual oleh pamannya kepada pak Hamdi dan pak Hamdi tidak mengetahui hal itu. Adapun kutipan lain yang menunjukkan percekcokan berikut ini.

"Dian : Kak, dengar ya. Aku tak lapar. Aku juga tak butuh makan. Untuk apa aku makan di kantin? Makanan hotel lebih enak dari pada di tempat pesakitan seperti ini".

"Fisha : Kok gitu?

"Dian : Gini aja dech, mending kak Fisha pulang aja ke rumah. Kak Fisha tidak usah ke sini”.

"Fisha : Maksudmu ini apa, dik? Astragfirllah kok kamu berkata seperti itu?"

"Dian : Alaaah, kayak kak Fisha ngak tahu aja. Apa pura-pura ngak tahu? Apa kamu begitu sangat bodoh sehingga belum juga menyadarinya?". 
"Fisha : Dik demi Allah. Kakak tidak mengerti. Kakak tidak tahu apa yang kau bicarakan ini."

"Dian : Kau pikir aku, ibu, adikku yang lain, mengajak Kak Desi menjenguk bang Fikri ke sini ini masih tidak jelas buatmu, heh?".

"Fisha :Aku benar-benar tidak paham. Dan aku tak mungkin meninggalkan Bang Fikri”.

"Dian : Sudahlah kak. Dia kakakku!

"Fisha : Dia Suamiku"

"Dian : Kak jangan membuat suasana tambah kacau"

"Fisha : Apa maksudmu, dik? Dia memang kakakmu, tetapi kakakmu adalah suamiku. Aku kakak iparmu, dik. Kenapa kau suruh aku pulang? Kenapa kau dan ibu baru datang setelah lima hari seperti ini. Apa kau pikir aku tak pernah menunggu suamiku?".

"Dian : Sudah, sudah. Aku tahu. Tapi, sekarang kau tak perlu menjaganya lagi. Ada kami, adiknya di sini. Juga ada ibu. Terimakasi kau telah menjaga kakakku. Lebih baik kau pulang kak!”.(Irawan, 2014:290-291)

Kutipan tersebut menunjukan percekcokan yang membuat Fisha dalam kebingungan dan kesedihan yang mendalam. Fisha tidak ingin meninggalkan suaminya yang sedang terbaring di rumah sakit itu, tetapi apalah daya Fisha tidak sanggup harus menlawan adik iparnya dan ibu mertuanya. Adapun kutipan yang menunjukkan percekcokan berikut ini.

\section{Penindasan}

Kutipan yang menyatakan penindasan terdapat pada kutipan-kutipan berikut ini.

"Wajah-wajah yang tadinya tampak senang, mulai menampakkan kebencian. Senyum yang ditampilkan, mulai tampak ketus. Hari-hari itu, Fisha mengalami apa yang tak pernah dia bayangkan sebelumnya sama sekali”.(Irawan, 2014:216) 
Kutipan tersebut menunjukan penindasan ibu mertua dan adik iparnya terhadap Fisha yang mengakibatkan Fisha merasa kaget dan heran karena wajah Ibu mertua dan adik iparnya berubah dan menunjukkan sifat asli mereka setelah Fikri suaminya tidak berada di rumah. Fisha merasa sedih dan tidak pernah terbayang olehnya sebelumnya. Adapun kutipan lain yang menunjukan penindasan berikut ini.

"Ibu Mertua : Pokoknya kau tak boleh lupa!"

"Fisha : Iya, Bu..."

“Dian : Dan jangan lupa teh buat ku!” imbuh Dian. "Aku mau sebelum aku bangun sudah ada secangkir teh di kamarku”.

"Fisha : Iya, Dik..."

"Dian : Kamu tu kenapa kak? Matamu kemana, heh? Ini masakan apa, heh? Kayak gini kau bilang ibumu punya warung? Hambar! O, bagaimana mungkin Fikri bisa menelan makanan seperti ini”. Apa-apaan ini? Kau bisa masak tidak sih, kak?”.

"Fisha : Maafkan kakak, dik. Nanti kakak akan perbaiki".

“Dian : Sampah- masakanmu lebih busuk dari sampah!”. Kalau memang tak bisa masak, kenapa kau tak bilang saja. Kenapa tidak menyuruh bi Inah saja, heh! Kau ingin meracun aku dan ibuku?”.

"Fisha : Maafkan saya, dik. Maafkan saya".

"Ibu Mertua : Cepat bersihkan. Lambat sekali kau”. (Irawan, 2014:220225)

Kutipan tersebut menunjukan penindasan yang dilakukan oleh ibu mertua dan adik iparnya terhadap Fisha. Fisha diperlakukan layaknya seorang pembantu bukan sebagai anak menantu bahkan bukan sebagai kakak ipar bagi Dian. Akan tetapi Fisha selalu bersabar dalam menghadapi ibu mertua dan adik iparnya, apapun yang dilakukan oleh Fisha seakan salah di mata mereka dan Fisha selalu meminta maaf. Adapun kutipan yang menunjukan penindasan berikut ini.

"Fisha yang terus membersihkan jendela mendengar keras ucapan adik iparnya itu. Fisha menarik nafas. Bersabar. Siapa adanya perempuan itu? Hatinya bertanya. Kerabat Fikri kah? Adik sepupunya kah? Atau siapa? 
Dia tau masakan kesukaan suamiku? Oh, dia masak apa? Makanan kesukaan suamiku yang bagaimana?’.(Irawan, 2014:234-235)

Setiap hari Fisha melakukan perkerjaan rumah seakan Fisha dianggap sebagai pebantu. Fisha membersihkan jendela dan kedatangan gadis asing yang tidak dikenalkannya itu membuat dia selalu bertanya siapakan dia, apakah hubungannya denga Fikri suaminya. Sampai-sampai makannya kesukaan Fikri saja gadis itu tahu.

Penindasan yang dilakukan Dian terhadap Fisha termasuk dalam konflik sosial yang berupa penindasan. Yang membuat pertanyaan besar dihati Fisha akan sosok seorang yang bernama Desi itu. Dian yang selalu membandingkan Fisha dan Desi sehingga membuat Fisha semakin terpojok. Adapun kutipan yang menunjukan penindasan berikut ini.

"Awas kalau kau ceritakan yang tidak-tidak pada Fikri. Kau harus bilang padanya bahwa kau tak mau diam. Kau terlalu keras bekerja. Kau telah kusuruh-suruh istirahat, tapi kau tak pernah mau mendengar kata-kataku. Awas kau harus berkata begitu nanti”.(Irawan, 2014:236-237)

Fisha diancam oleh ibu mertuanya. Agar tidak memberi tahu apa yang terjadi sebenarnya dan apa yang dilakukan Ibu mertua dan adik iparnya kepada dirinya. Penindasan yang dilakukan termasuk dalam konflik sosial yang berupa penindasan ibu mertua, dan Dian kepada Fisha. Ibu mertua Fisha dan Dian mengancam Fisha agar tidak berbicara yang sebenarnya tentang perlakuan mereka terhadap Fisha. Adapun kutipan yang menunjukkan penindasan berikut ini.

“O, kejamnya kau hidup berumah tangga tanpa bisa punya anak. Sia-sia rumah tangga mu. Untuk apa kau terus membina kehidupan rumah tangga itu?’.(Irawan, 2014:262)

Kutipan tersebut menunjukan penindasan yang dilakukan oleh Ibu mertuanya terhadap Fisha. Yang mengakibatkan Fisha semakin merasa bersalah karena masih belum bisa menjadi istri yang baik buat suaminya dan belum bisa menjadi menantu yang baik buat ibu mertuanya. Fisha merasa tertekan karena 
masih belum bisa memberikan buat hati kepada suaminya. Adapun kutipan yang menunjukan penindasan berikut ini.

“Kau ikut saja. Jangan banyak tanya!!” Bentak Fikri”. (Irawan, 2014:329)

Fisha yang bertanya kepada Fikri, dan Fikri membentak Fisha pedahal selama dia dinikahi oleh Fikri belum pernah Fikri berbicara kepadanya dengan nada yang tinggi. Penindasan yang dilakukan Fikri terhapat Fisha yang termasuk dalam konflik sosial yang berupa penindasan. Yang mengabitkan Fisha merasa heran karena selama ini Fikri belum pernah memperlakukannya seperti saat ini.

\section{a. Pertentangan}

"Maafkan aku, suamiku. Maafkan aku telah menyembunyikan penyakit ini dari penglihatanmu selama ini”. Ucap Fisha terbata-bata (Irawan, 2014:12)

Kutipan tersebut menunjukan pertentangan antara Fikri dan Fisha yang mengakibatkan Fikri marah terhadap Fisha karena telah menyembunyikan penyakitnya dari penglihatan Fikri. Adapun kutipan yang menunjukan pertentanagan berikut ini.

"Fisha tak sanggup berada dalam situasi seperti ini. Jiwanya resah. Jiwanya gelisah. Didepannya, ada dua pemuda; yang satu sudah bertahuntahun dikenalnya; dan yang satu belum lama namun telah mengantarkan hatinya atas nama Allah Ta'ala".(Irawan, 2014:165)

Fisha merasa bingung harus memilih antara Hamzah yang telah lama dikenalnya atau Fikri yang belum lama dikenalnya. Hamzam selalu menuntut jawaban dari Fisha atas perasaan dimilikinya terhadap Fisha. Kutipan tersebut menunjukan pertentangan antara Fisha, Fikri dan Hamzan. yang membuat Fisha merasa tidak sanggup dalam menghadapi masalah tersebut. Karena Fisha harus memilih antara Fikri dan Hamzan. Adapun kutipan yang menunjukan pertentangan berikut ini.

"Bukan begitu, Hamzah. Aku bingung terhadap diriku sendiri”.(Irawan, 2014:170) 
Kutipan tersebut menunjukan pertentangan antara Hamzan dan Fisha yang mengakibatkan Fisha merasa terpojok Fisha selalu ditentang oleh Hamzah karena pilihan Fisha. Adapun kutipan yang mennjukan pertentangan terdapat pada.

"Fisha mengangguk dan tersenyum. Tetapi perasaannya menjadi ragu saat melihat wajah adiknya dan menimbang apa yang menjadi keinginannya tadi”,(Irawan, 2014:203)

Kutipan tersebut menunjukan pertentangan antara Fisha dan keluarga Fikri. Pertentangan tersebut masuk dalanm konflik sosial yang berupa pertentangan. Yang mengakibatkan perasaan Fisha bimbang karena pasti ada sesuatu yang terjadi pada Bundanya dan adinya Amirah. Karena, tidak biasanya Amirah bersifat seperti itu, Fisha yakin pasti ada yang terjadi antara Bunda dan Ibu Mertuanyan.

\section{Konflik internal dalam novel Air Mata Tuhan karya Aguk Irawan M.N}

Berdasarkan analisis yang dilakukan oleh peneliti, di dalam novel Air Mata Tuhan karya Aguk Irawan M.N, terdapat banyak kutipan yang menggambarkan konflik batin internal tokoh utama.

\section{a. Harapan-Harapan}

"Ya, Allah, berilah kekuatan pada ku di hari ini. Cukupkan kesabaran di dadaku". (Irawan, 2014:1)

Kutipan tersebut mengambarkan ketabahan dan kesabaran hati Fisha menghadapi pernikahan suaminya dengan wanita lain. Konflik batin dalam kutipan tersebut terlihat dari ketabahan dan kesabaran Fisha. Kutipan lain yang menunjukan harapan-harapan berikut ini.

"Fisha hanya bisa menelan ludah. Dalam hati, dia pun berujar, "Ya Allah.

Berilah kesabaran padaku. Bahagiakanlah suamiku. Relakan hatiku untuk mendapatkan sahabat baru dalam rumah tanggaku...”. (Irawan, 2014:6)

Kutipan tersebut menunjukan harapan Fisha kepada Allah agar selalu memberikan kesabaran kepadanya. Agar merelakan hatinya untuk mendapatkan sahabat baru di rumahnya dan agar suaminya selalu bahagia. Walaupun hatinya menangis dan menjerit menerima kenyataan ini tapi Fisha harus bisa merelakan 
semuanya demi kebahagiaan suaminya. Kutipan lain yang menunjukkan harapanharapan berikut ini.

"Apa dosaku? Apa kesalahanku? Kujaga diriku dengan sebaik-baiknya, setelah kecerobohan yang telah kuperbuat dulu, tetapi tetap saja kau angkat bayi dari rahimku?’.(Irawan, 2014:268-269)

Kutipan ini menunjukan jeritan hati Fisha. Fisha menangis atas apa yang terjadi atas dirinya, Fisha menyesal karena tidak lebih berhati-hati dalam menjaga kandunganny. Fisha hanya bisa merenungi nasibnya.

\section{b. Pertentangan Antar Dua Keinginan}

"Perasaan Fisha bersilang-sengkarut menyaksikan Fikri, sang suami tercinta, duduk bersanding dengan Desi. Ada nafsu yang meneriaki hatinya untuk menyeru, "Jangan lakukan, Ayah. Jangan! Lihatlah aku, betapa aku sangat mencintaimu. Oh, hati perempuan mana yang rela dimadu. Jangan, Ayah. Kasihani aku dengan cintamu. Beri kesempatan pada ku untuk memiliki momongan, buah cinta kita”. (Irawan, 2014:5)

Kutipan tersebut menunjukan adanya harapan antar dua keinginan. Fisha ikhlas Fikri menikah dengan wanita lain karena, di dalam agamanya poligami tidak diharamkan dan Fisha juga sadar bahwa dia tidak bisa memberikan momongan kepada suaminya. Akan tetapi, di dalam hatinya Fisha sulit untuk menerima kenyataan yang ada. Kutipan lain yang menunjukan pertentangan antar dua keinginan berikut ini.

"Jantung Fisha berdetak semakin kencang mendengar suaminya mengucapkan qabul atas ucapan ijab Desi yang diwakili oleh penghulu itu. Fisha mendesah. Sejenak dia tatap pandangan itu, sejenak dia menunduk. Dan sekuat-kuat hatinya, sekuat-kuatnya jiwanya yang diwujudkan dalam senyumannya, tetap saja bola matanya tak sanggup membendung tumpahnya air mata”. (Irawan, 2014:4-5)

Kutipan di atas Fisha berusaha untuk tersenyum pedahal hatinya menangis saat mendengar Fikri mengucapkan qabul terhadap Desi yang sebentar lagi akan menjadi teman barunya di dalam rumah tangganya dengan Fikri. Adapun kutipan yang menunjukan pertentangan antar dua keinginan berikut ini. 
"Fisha merasa berada pada kondisi yang paling berat disepanjang hidupnya”.(Irawan, 2014:166)

Kutipan tersebut menunjukan Fisha berada dalam kondisi paling berat dalam hidupnya. Fisha harus berkerja untuk membantu bundanya mencari uang buat biaya sekolah Amirah atau Fisha harus terus meneruskan kuliahnya. Adapun kutipan yang menunjukan pertentangan antar dua keinginan berikut ini.

"Fisha belum berani menceritakan dua surat dari dua pemuda itu. Biarlah Bunda beristrahat terlebih dahulu. Tentang laundry, mari kita serahkan kepada Allah".(Irawan, 2014:167)

Kutipan tersebut menunjukan Fisha merasa bingung dia harus memilih Fikri pria yang baru saja dikenalnya atau Hamzah pria yang sudah lama dikenalnya untuk menjadi pendamping hidupnya. Adapun kutipan yang menunjukan pertentangan antar dua keinginan berikut ini.

"Fisha semakin tersudut. Adakah ia memang berarti melukai hati dan perasaan Hamzah apabila ia memutuskan untuk memilih Fikri”.(Irawan, 2014:170)

Kutipan tersebut mengambarkan bahwa Fisha merasa tersudut dengan dua pilihan. Fisha merasa dia benar-benar akan melukai hati dan perasaan Hamzah apabila dia memutuskan untuk memilih Fikri dibanding Hamzah. Pertentanagn antar dua keingin termasuk dalam konflik batin yang berupa pertentangan antar dua keinginan. Adapun kutipan yang menunjukan pertentangan antar dua keingian berikut ini.

"Bunda, adakah aku salah jika aku terima Fikri sebagai pedamping hidupku, Bunda? Adakah aku keliru bila aku meninggalkan Hamzah demi dia? Zalimkah aku dengan perasaan ku? Tolong aku bunda”.(Irawan, 2014:172)

Kutipan tersebut Fisha bingung karena dia akan memutuskan pilihannya kepada Fikri. Akan tetapi, bagaimana dengan Hamzah jika Hamzah tahu pilihannya adalah Fikri. Adapun kutipan yang menunjukan pertentangan antar dua keinginan berikut ini. 
"Mendengar nasehat Bunda, Fisha menunduk. Air matanya mengalir deras. Fisha pejamkan mata. Pada ketika itu, yang tampak di pelupuk matanya adalah wajah ayahnya".(Irawan, 2014:173)

Kutipan tersebut mengambarkan adanya pertentangan antar dua keinginan yang termasuk dalam konflik batin. Fisha meminta pendapat bundanya apakah Fikri atau Hamzah yang akan dipilih untuk menjadi pendamping hidupnya. Fikri yang mencintai Fisha karena Allah semata akan tetapi, Hamzah tidak pernah mengatakan hal serupa. Adapun kutipan yang menunjukan pertentangan antar dua keinginan berikut ini.

"kabar yang mengagetkan dari adiknya Amirah itu teramat mencemaskan

Fisha. Hingga beberapa kali membuat air matanya menetes”.(Irawan, 2014:210)

Kutipan tersebut menunjukan Fisha kaget mendengar kabar dari adiknya bahwa bunda dan adiknya akan kembali kekamung halaman mereka. Sedangkan Fisha belum sempat bertemu sama bunda dan adiknya Fisha ingin sekali bertemu sama bunda dan adinya. Akan tetapi dia juga tidak mau meninggalkan momen sebagai pengantin baru. Adapun kutipan yang menunjukan pertentangan antar dua keinginan berikut ini.

"Maafkan aku, Bunda. Aku tidak tahu, kenapa ibu dan adik iparku begitu benci terhadap ku. Semua yang ku kerjakan, semua yang ku lakukan, di rumah ini, selalu saja salah di mata mereka. Bunda, oh bunda aku rindu engkau".(Irawan, 2014:225-226)

Fisha merasa sangat bersalah kepada bunda dan adiknya, karena Fisha bingung kenapa ibu mertua dan adik iparnya sangat membencinya. Semua yang Fisha kerjakan seakan salah dimata mereka, dan Fisha menangis menginggat bundanya diperlakukan seperti itu. Kutipan lain yang menunjukan pertentangan antar dua keinginan berikut ini.

"Fisha mengigit bibir. Dia ingin bangun dari pembaringan, tetapi dirasakannya dia lemas sekali. Tak berdaya. Fisha hanya bisa menangis. Hatinya menjerit”.(Irawan, 2014:237) 
Kutipan tersebut menunjukakan Fisha ingin bangkit dari pembaringannya. Akan tetapi rasa sakit itu seakan membuatnya tak berdaya dan Fisha hanya bisa menangis. Adapun kutipan yang menunjukkan pertentangan antar dua keinginan berikut ini.

"Fisha menggigit bibirnya yang pucat putih itu. Dia ingin mengatakan hal yang sebenar-benarnya, tetapi tatapan mata ibu mertuanya yang berdiri di belakang Fikri membuatnya terdiam. Sepasang bibir Fisha yang pucat pasi itu hanya bisa bergeyar".(Irawan, 2014:239)

Kutipan tersebut menunjukan Fisha yang ingin mmengatakan yang sebenarnya terjadi kepada Fikri. Tetapi, Fisha takut kepada ibu mmertuanya yang menatapnya dengan tatapan tajam. Adapun kutipan yang menunjukan pertentangan antar dua keinginan berikut ini.

"Bahkan tumpahan air mata itu tak bisa mengobati kepedihan Fisha.

Hatinya pun menjerit luka”.(Irawan, 2014:268)

Kutipan tersebut menunjukan Fisha hanya bisa menangisi semua yang menimpanya. Pedahal Fisha sangat-sangat menginginkan bayinya akan tetapi Tuhan berkendak lain.

\section{SIMPULAN}

Konflik eksternal yang terdapat dalam novel Air Mata Tuhan karya Aguk Irawan M. N berdasarkan analisis yang peneliti lakukan yaitu konflik sosial yang berwujud masalah penuduhan, percekcokan, penindasan, dan pertentangan. Konflik internal yang terdapat dalam novel Air Mata Tuhan karya Aguk Irawan M. $\mathrm{N}$ berdasarkan analisis yang peneliti lakukan yaitu konflik batin yang berupa harapan-harapan, dan pertentangan antar dua keinginan

\section{DAFTAR RUJUKAN}

Faruk. (2012). Pengantar Sosiologi Sastra. Yogyakarta: Pustaka Pelajar. Irawan M. N, Aguk. (2014). Air Mata Tuhan. Depok: Imania. 
PARAMASASTRA, Vol. 3, No. 1 - Maret 2016

Nurgiyantoro, Burhan. (2013). Teori Pengkajian Fiksi. Yogyakarta: Gajah Mada University Press. 